\title{
Concessivas num corpus da Idade Moderna
}

\author{
Ana Luísa Costa \\ Centro de Linguística da Universidade de Lisboa \\ Escola Superior de Educação do Instituto Politécnico de Setúbal
}

\begin{abstract}
Based on a corpus linguistics analysis, this study proposes a description of the syntactic distribution and semantic functioning of three concessive connectives in a Portuguese epistolary corpus from Early Modern Ages, the P.S. Post Scriptum. These connectives, embora, mesmo que and ainda que, are considered the most frequent conjunctions in Contemporary European Portuguese. Corpus analysis reveals a different diachronic path for each one. In the beginning of the $20^{\text {th }}$ century, while embora frequency of use grows, it is evident the decrease of ainda $q u e$, with consequences in the concessive conjunctions system.
\end{abstract}

Keywords/Palavras-chave: connectives/conectores, concessive conjunction/conjunção concessiva, grammaticalization/gramaticalização, corpus linguistics/linguística de corpus.

\section{Introdução}

Faz parte do conhecimento sobre língua portuguesa comumente partilhado a origem de algumas palavras, como é o caso da origem da conjunção subordinativa concessiva embora, cuja etimologia, atestada em vários dicionários, se associa à locução em boa hora. Menos acessível é o conhecimento dos trilhos seguidos ao longo dos séculos por embora e por outros conectores, que, antes de estabilizarem o seu uso conjuncional contemporâneo, seguiram caminhos de gramaticalização e subjectivização nem sempre fáceis de atestar (Lima, 1997).

Com a finalidade de descrever o funcionamento sintático e semântico de três dos mais frequentes conectores concessivos, embora, mesmo que e ainda que, no presente estudo

1 Trabalho desenvolvido no âmbito do projeto P.S. - Post Scriptum, Arquivo Digital de Escrita Quotidiana em Portugal e Espanha na Época Moderna (European Research Council, 7FP/ERC Advanced Grant - GA 295562). 
apresenta-se uma análise das suas ocorrências num corpus que abarca produções escritas do português da Idade Moderna ao longo de quatro séculos: o corpus epistolográfico P.S. Post Scriptum $^{2}$. No primeiro ponto, refere-se o estado da arte quanto a estudos de concessivas em corpora e, no segundo ponto, descrevem-se os procedimentos metodológicos seguidos na análise. Seguidamente, apresentam-se os resultados de uma abordagem quantitativa, de frequências de uso, e alguns dados ilustrativos de propriedades sintáticas e semânticas de cada um dos conectores. No último ponto, sistematizam-se algumas considerações, que podem constituir pistas para trabalho futuro.

\section{Concessivas em estudos de corpora}

O presente estudo do percurso diacrónico dos conectores embora, mesmo que e ainda que tem na base critérios de frequência e de complexidade ${ }^{3}$ semântica, os quais são utilizados em outros estudos de corpora do português contemporâneo. Estes estudos, embora recorram a corpora de natureza diferente e com objetivos distintos, apresentam dados consensuais quanto à proeminência destes três conectores no paradigma dos contrastivos.

Um trabalho de referência para o estudo de conexões contrastivas (adversativas e concessivas) em inglês, alemão, espanhol e português é a obra Contrast, na qual Elisabeth Rudolph recorre a um corpus escrito, constituído por textos narrativos literários do século XIX e XX e textos jornalísticos do século XX. Relativamente à análise de conectores concessivos em português, neste estudo, estabelece-se como escala de frequência a que se apresenta em (1).

(1) Escala de frequência de Rudolph (1996)

ainda que $>$ embora $>$ apesar de $>$ mesmo que

Rudolph (1996, p. 5)

Nesta escala, que, segundo a autora, representa não só frequência, mas também a funcionalidade semântica de cada conector, a locução conjuncional ainda que é o conector que

2 O corpus P.S. Post Scriptum pode ser consultado em http://ps.clul.ul.pt/pt/index.php?action=home. O projeto P.S. - Post Scriptum visa a edição digital de cerca de 7000 cartas particulares, portuguesas e espanholas, mantidas como prova em processos judiciais civis e religiosos.

3 O conceito «complexidade» é usado em sentido lato, associado a plurifuncionalidade sintática e semântica. 
ocupa um lugar de maior destaque. Seguem-se dois conectores conjuncionais de concessivas canónicas, embora e apesar de, e em quarto lugar encontra-se o conector condicional-concessivo mesmo que. As tabelas de conectores de Rudolph incluem outras conjunções e locuções concessivas menos frequentes, ainda que reconhecidamente importantes em alguns tipos de texto. Considerando a totalidade dos conectores encontrados, a autora destaca como mais frequentes os dois primeiros: ainda que e embora.

Outro estudo desenvolvido com uma análise de frequências de concessivas em produções escritas é a dissertação de Costa (2010), a qual integra um corpus de textos de carácter argumentativo, com produções escritas de crianças a partir dos nove anos, de adolescentes e de adultos de um grupo de controlo. Neste caso, a escala de frequência encontrada é a que se reproduz em (2).

(2) Escala de frequência de Costa (2010)

apesar de $>$ embora $>$ mesmo que $>$ ainda que

Costa (2010, p. 181)

Neste estudo, os conectores concessivos mais frequentes são apesar de e embora, quase sem diferenças significativas: a frequência média ${ }^{4}$ do primeiro corresponde a 0,59 , muito próxima da frequência média de embora, que é 0,44 . De acordo com esta escala, os outros dois conectores são bem menos frequentes: mesmo que tem uma frequência média de apenas 0,23 e ainda que é pouco usado nestes textos, com um valor médio de 0,13. Assim, com base neste corpus, encontra-se o resultado inverso relativamente a ainda que, o qual, neste caso, é o conector menos frequente.

De qualquer forma, se a comparação entre as duas escalas deixa perceber diferenças na ordem relativa entre conectores mais frequentes, saliente-se que, observando o conjunto mais vasto dos conectores do paradigma dos concessivos, é consensual a consideração dos mesmo quatro como os mais frequentes no português europeu contemporâneo (PEC). Deste modo, os

4 A frequência média de cada conector equivale à divisão do número de conectores pelo número de textos. 
resultados de Rudolph (1996) e de Costa (2010) fundamentam a seleção de apenas alguns conectores para o estudo longitudinal do funcionamento de conectores concessivos. De entre os quatro conectores mais frequentes, exclui-se o tratamento de apesar de, por ser o único que ocorre em contextos não finitos, circunscrevendo-se a análise aos três conectores que (i) integram concessivas finitas, (ii) são de natureza conjuncional e (iii) são os mais frequentes.

Atendendo a outros trabalhos sobre concessivas que têm por base estudos de corpora, para a análise do percurso de gramaticalização de embora, Pinto de Lima (1997), no artigo «Caminhos semântico-pragmáticos da gramaticalização: o caso de embora», recorre a dados do Corpus Informatizado do Português Medieval (CIPM) e do Corpus de Referência do Português Contemporâneo (CRPC), salientando, na nota 6, a ausência de dados informatizados para o Português Moderno: «Infelizmente não existe nenhum corpus informatizado que cubra o período dos séculos XVI a XIX (pois o CIPM cobre só os séculos XIII a XV e o CRPC os séculos XIX (2. ${ }^{a}$ metade) e XX. É minha convicção que, no futuro, uma informatização de textos portugueses dos séculos XVI a XIX irá permitir precisar e aprofundar a análise da gramaticalização de embora para além do que agora é possível.» (idem, p. 654). Ora, os dados do corpus PS-CARDS, usados neste estudo de concessivas da Idade Moderna, vêm justamente suprir a lacuna identificada.

\section{Metodologia}

Para o estudo do funcionamento sintático-semântico de embora, mesmo que e ainda que na Idade Moderna, analisaram-se $923^{5}$ cartas particulares escritas entre 1516 e 1833 , as quais correspondem a um total de 323.571 tokens. A carta mais antiga data de 1516, havendo uma carta do século XVI sem informação quanto ao ano de produção. No que respeita à carta mais recente, a data 1833 coincide com o limite temporal superior definido para o projeto P.S. Post Scriptum, que recolhe cartas produzidas entre 1500 e 1833. Fica, portanto, coberto o lapso de tempo mencionado por Pinto de Lima (ibidem).

5 Este número corresponde à totalidade de cartas disponíveis para download em maio de 2014. Estando o projeto em desenvolvimento, o corpus, tanto de cartas portuguesas, como de cartas espanholas tem crescido significativamente. 
Autores como Flamenco García (1999) estabelecem uma estreita associação entre as estruturas concessivas e a argumentação, pelo que o género discursivo deve ser um critério a ter em consideração na pesquisa de conectores concessivos. Num corpus epistolográfico de escrita do quotidiano, o tipo de sequências textuais varia consideravelmente em função do contexto de produção da carta (Costa, García Prieto e Pampliega Pedreira, 2014), havendo, mesmo em cartas em que o principal objetivo é dar notícias, sequências de carácter argumentativo associadas a pedidos, súplicas ou explicações do autor.

Independentemente do género discursivo, o principal problema ao estudar conectores concessivos em corpora, particularmente quando se tem como medida de referência a frequência, é exatamente a sua reduzida frequência de ocorrência, em comparação com outros conectores (Costa, 2010; Prada, 2000; Rudolph, 1996). Por exemplo, na totalidade das 923 cartas, encontram-se 938 mas, o que corresponde a uma frequência superior a um conetor por carta, ao passo que no mesmo conjunto de textos se encontram apenas 6 embora $^{6}$.

Para a análise das frequências de ocorrência, numa abordagem quantitativa, recorreu-se à ferramenta WordList, do WordSmith Tools (0.6). De forma a tornar comparáveis os resultados por século, os valores apresentados correspondem a uma média de ocorrências de cada conector por texto epistolar (cf. nota 4). A descrição de propriedades sintáticas e semânticas, que depende de uma análise de contextos linguísticos, foi suportada pelos dados extraídos com o Concord, também do WS. Este nível de análise foi orientado por dois tópicos: a distribuição sintática de cada conector e os seus valores semânticos.

Numa tentativa de robustecer os resultados da análise, para cada conector, a pesquisa de informação foi complementada com mais três passos: (i) o controlo dos resultados, pela comparação com dados de outro corpus epistolográfico da mesma época, (ii) a consulta de obras lexicográficas também da Idade Moderna e (iii) a extensão da análise a um subcorpus de cartas equivalentes do início do século XX.

De forma a consolidar a análise de cartas particulares escritas por mãos menos hábeis (Marquilhas, 2012), procedeu-se a um estudo comparativo dos conectores concessivos usados nas

6 No corpus de Costa (2010), constituído apenas por textos de carácter argumentativo, encontra-se uma desproporção igualmente assinalável entre embora, um dos conectores mais frequentes em português, e o seu correlato mas. Concretamente, em contraste com um total de 302 ocorrências de mas, há 29 ocorrências de embora. 
cartas particulares escritas por Marquesa da Alorna, uma autora erudita, disponibilizadas no corpus Tycho Brahe ${ }^{7}$. Trata-se de um subconjunto de textos do mesmo género: 41 cartas particulares contendo 45008 tokens. Estas cartas foram produzidas no século XVIII por uma escritora que recorre com frequência a sequências textuais argumentativas e que domina as regras do registo escrito culto.

À semelhança da pesquisa desenvolvida em Lima (1997) para colmatar a falta de dados entre os séculos XVI e XIX, procedeu-se à consulta de obras lexicográficas publicadas na época de escrita das cartas do P.S. Post Scriptum, com base em mais um recurso de um projeto em humanidades digitais, o Corpus Lexicográfico do Português ${ }^{8}$. Tratando-se do período em questão, a reflexão gramatical publicada na época sobre as estruturas em estudo não podia ser ignorada. Com a consulta das entradas sobre cada conector em dicionários e também em algumas gramáticas, não se pretende, naturalmente, obter confirmação da descrição do funcionamento das estruturas encontradas nos dados de produção escrita. Estas obras consagram a reflexão metalinguística de gramáticos e lexicógrafos da época, o que, fundamentalmente, faculta um acesso indireto à estabilização de processos e de estruturas em fases mais antigas da língua.

Finalmente, visto que os dados indiciam histórias inacabadas para dois dos conectores, embora e ainda que, analisou-se a frequência e o funcionamento dos mesmos conectores num subconjunto de 221 cartas do início do século XX (86.672 tokens). Estas cartas, que à semelhança das cartas do P.S. Post Scriptum também contam «language histories from below» (Elspaß, 2012, p.45), foram produzidas em três contextos históricos, I Guerra Mundial, Guerra Colonial e emigração, e encontram-se no corpus FLY ${ }^{9}$.

\section{Para a história dos conectores concessivos}

Em diversos estudos sobre subordinação concessiva no PEC (Brito, 2003; Costa, 2010; Lobo, 2003; Lopes, 1983; 1989; Peres, 1997; Varela, 2000), o conector embora surge associado ao valor semântico de factualidade, como em (3), ao passo que a locução mesmo que expressa a valores típicos de condicionais, como se exemplifica em (4).

7 Para mais informações sobre o corpus Tycho Brahe, consulte-se http://www.tycho.iel.unicamp.br/ tycho/corpus

8 Para mais informações sobre o Corpus Lexicográfico do Português, consulte-se http://clp.dlc.ua.pt/Inicio.aspx

9 Para mais informações sobre o corpus FLY, consulte-se http://fly.clul.ul.pt/ 
(3) Embora a Rosa lhe escreva cartas, o Pedro não lhe responde.

(4) Mesmo que a Rosa lhe escreva cartas, o Pedro não lhe responde.

Alguns autores (Costa, 2008; 2010; Peres et al., 1999) têm proposto análises para a plurifuncionalidade de ainda que, locução que, em enunciados como (5), tem um valor ambíguo entre factual, como se pode verificar pela paráfrase em (5'), e hipotético, como se ilustra em $(5$ ') $)$.

(5) Ainda que a Rosa lhe escreva cartas, o Pedro não lhe responde.

(5') Ainda que a Rosa, de facto, habitualmente, lhe escreva cartas, o Pedro não lhe responde.

(5') Ainda que a Rosa lhe escreva cartas, o que pode vir a acontecer, o Pedro não lhe responde.

O facto de os três conectores introduzirem enunciados frásicos finitos abre a possibilidade de comutação de ainda que por embora em enunciados factuais, e de troca entre aquela locução e mesmo que em enunciados condicionais. Desde quando se estabeleceu esta especialização de valores semânticos entre os conectores? Como era a distribuição sintática de cada um durante a Idade Moderna?

\subsection{Uma história recente para embora}

Como antes se referiu, o percurso de gramaticalização de embora foi estudado de forma aprofundada em Lima (1997). No século XVI, em exemplos como o ilustrado em (6), da Comédia de Rubena, embora é uma expressão adverbial que mantém ainda a leitura composicional equivalente à de uma expressão de bom auspício.

(6) Ora yde vos yeramaa / E ama venha embora, 


\section{Gil Vicente [1521/1562]}

Neste excerto, embora, ou «em boa hora», ainda que associado ao verbo de movimento vir, pode interpretar-se por oposição a «em má hora», como manifestação positiva relativamente à chegada da ama. Sendo esta uma obra do século XVI, poder-se-á pressupor que, no decurso da Idade Moderna, esta expressão adverbial funciona como expressão de aprovação e passa, por um processo de inferência, a expressar «aceitação» por parte do falante, começando a assumir também um valor de concessão. Segundo Pinto de Lima, a ideia de concessão começa por ser veiculada a nível pragmático por via de uma implicatura conversacional e é, mais tarde, convencionalizada, passando esse valor e ser veiculado a nível semântico (Lima, idem, p. 648).

A ocorrência da palavra embora no corpus P.S. Post Scriptum é muito escassa. Em 923 cartas, há apenas 19 itens, dos quais apenas 6 veiculam um valor contrastivo concessivo, com a distribuição por século que se apresenta na tabela 1 .

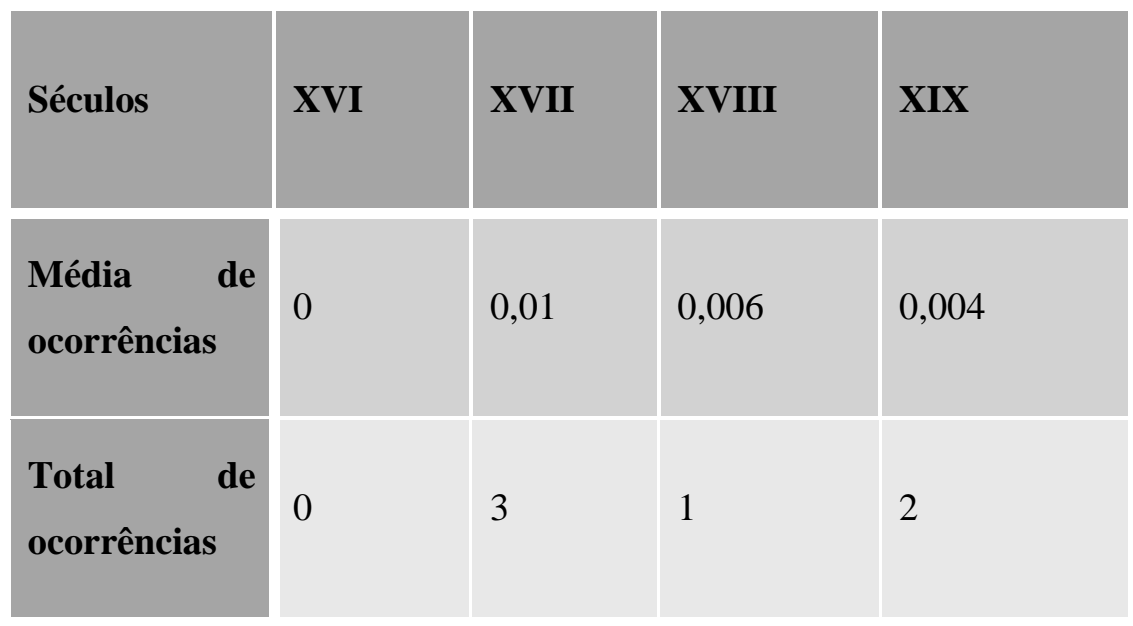

Tabela 1: ocorrências de embora com valor contrastivo no corpus P.S.

As restantes 13 ocorrências de embora encontram-se em construções com o verbo ir ou vir e são ambíguas entre o sentido de «bom augúrio» ou «aprovação» e o valor atual de movimento, associado a estes verbos, como acontece no exemplo (7). 
(7) lhe peso ma guarde m(ui)to bem guardada p(ar)a quamdo eu em/bora for ma dar (PSCR1255, 1612)

Quanto aos 6 embora contrastivos, em todos os contextos apresentam uma distribuição de expressão adverbial, ocorrendo a maioria em posição pós-verbal, conforme os exemplos (8) e (9).

(8) inda v(osa) m(erce) não achou nesta que eu lhe meresia mandar me hüa/ sertidão da divida do milão seja embora dar grasas a / deos com tudo (PSCR1255, 1612)

(9) desde já lhe asevero q(ue) jamais de/zejarei utilizar-me dos dois extremos: viva m(ui)to embora $\mathrm{p}(\mathrm{o}) \mathrm{r}$ lon/gos annos a pár das riquezas, q(ue) eu a pár da indegencia pas/sarei o resto de meus dias

(CARDS0177, 1827)

Em (8), o contraste entre a expetativa de receber a certidão de dívida e, apesar de não a ter recebido, dar graças a Deus é marcado por um embora que ocorre a seguir à forma verbal seja, posição que exclui a possibilidade de se tratar de um funcionamento conjuncional. A mesma posição, típica de alguns advérbios conectivos, é ocupada por muito embora, em (9), marcando o contraste entre viver a par de riquezas e passar os dias na indigência. Neste segundo exemplo, muito embora, enquanto expressão adverbial de contraste, já destituída da leitura composicional do século XVI, pode atestar uma antiga construção de expressão de intensidade, por integrar o advérbio muito, que sobreviveu até ao português do século XXI, a par da gramaticalização de embora como conjunção.

O único exemplo em que este conector ocupa uma posição prototípica de conjunção encontra-se em (10).

(10) deve de estar louco / q(ue)m Comete semelhantes Crimes; muito embora / seja perdoado (CARDS0094, 1829) 
No exemplo (9), já da primeira metade do século XIX, embora aparece integrado na expressão adverbial modificada por muito, o que não garante uma análise enquanto conjunção. Em suma, nas produções de embora do corpus P.S. Post Scriptum, encontram-se dois tipos de configuração adverbial, representadas em (11), sendo a posição pré-verbal, atestada numa carta do século XIX, o caminho para a gramaticalização da conjunção concessiva que conhecemos na atualidade.

(11) Configurações de construções com embora

-Posição pós-verbal (5 exemplos)

- $\mathrm{V}+$ embora

- $\mathrm{V}+$ muito embora

-Posição pré-verbal (1 exemplo)

- muito embora $+\mathrm{V}$

O confronto com dados de outros corpora confirma o baixo índice de frequência de uso deste conector no Português Moderno ${ }^{10}$. No subcorpus de cartas de Marquesa de Alorna não há qualquer ocorrência de embora. Mesmo considerando as referências a esta palavra no Corpus Lexicográfico do Português, encontram-se uns exíguos 87 registos (que contrastam, por exemplo, com 8154 registos de mas).

Complementarmente, a análise de alguns verbetes e abonações de embora em obras lexicográficas entre os séculos XVI e XVIII indicia o carácter tardio da sua distribuição como conjunção, ainda que já haja referências ao seu uso com valor semântico contrastivo.

Em (12), exemplo retirado de um verbete do dicionário de português-latim de Agostinho Barbosa, ilustra-se uma atestação ainda com o significado original de bom auspício, remetendo para o valor semântico usado em estádios anteriores da língua, como o atestado na Comédia de Rubena.

10 Para a periodização da História da Língua Portuguesa, consulte-se Martins (2003, p. 54). 
(12) “Em boa hora” aliàs “embora” per syncopam. Bono auspicio.

Agostinho Barbosa (1611) Dictionarium Lusitanico Latinum (CLP)

Note-se que esta atestação do valor de bom auspício, num dicionário de 1611, concorre com o valor contrastivo encontrado no exemplo (8), de uma carta de 1612.

Já no exemplo (13), retirado do Vocabulario Portuguez e Latino, regista-se a distribuição típica de expressão adverbial, com a posição pós-verbal, mas evidencia-se já um valor interpretável como contrastivo, mais próximo de uma concessão orientada para o falante.

(13) Seja embora, como queres.

Rafael Bluteau (1712-28) Vocabulario Portuguez e Latino (CLP)

Como destaca Pinto de Lima (1997, p. 649), a primeira edição do dicionário de Morais ${ }^{11}$, de 1789, que se transcreve em (14), contém dados particularmente interessantes para a história de embora.

(14) EMBORA, s.f. (composto de em, boa, ho/ra) ou mascul. Hist. dos Tavoras f. 117. E poco / antes; usa se sustantiv. quando dizemos v. g. ,, / dar emboras v. g. ,, da victoria, como parabéns. / Freire: Palemer. 4. P. f. 6. v. diz ,, as emboras. / § Usa-se adverbialmente v. g. ,, vá-se embora, / embora murmure a gente; ou só „, embora „, por / seja assim, ou não me importa.

Antonio de Morais da Silva (1789) Diccionario da Lingua Portugueza (BBM) [a transcrição é minha]

Apesar de, nesta entrada, se descrever o funcionamento adverbial, associado ao valor de aceitação por parte do falante, há uma abonação, destacada em (15), que pode ser tomada como um indício do aparecimento do funcionamento conjuncional, com valor concessivo:

11 Note-se que este verbete atesta também um funcionamento substantivo desaparecido, em dar emboras, com o significado de parabéns, à semelhança do que existe em espanhol, em la enhorabuena, herdeiro mais direto da expressão de bom auspício. 
De todos os dados analisados, este exemplo do século XVIII é o primeiro caso em que embora cumpre os critérios de conjunção, estando em posição pré-verbal, selecionando presente do conjuntivo e, cumulativamente, operando valor concessivo. Porém, só com uma incursão pelos dados do século passado se consegue ter mais atestações do seu funcionamento como conjunção subordinativa concessiva.

Nas cartas particulares do corpus FLY, em contraste com a escassez de embora nas cartas da Idade Moderna, encontram-se 44 ocorrências de embora, das quais 13 (29,5\%) são construções associadas a verbos de movimento, como o verbo $i r$. De forma bastante significativa, há apenas um exemplo do uso adverbial da expressão muito embora e a maioria das ocorrências, num total de $30(68,2 \%)$, corresponde a conjunções concessivas.

Considere-se agora a totalidade das ocorrências de embora nos dois corpora epistolares, o P.S. Post Scriptum (séculos XVI a XIX) e o FLY (século XX), cujos valores se sintetizam na tabela 2 .

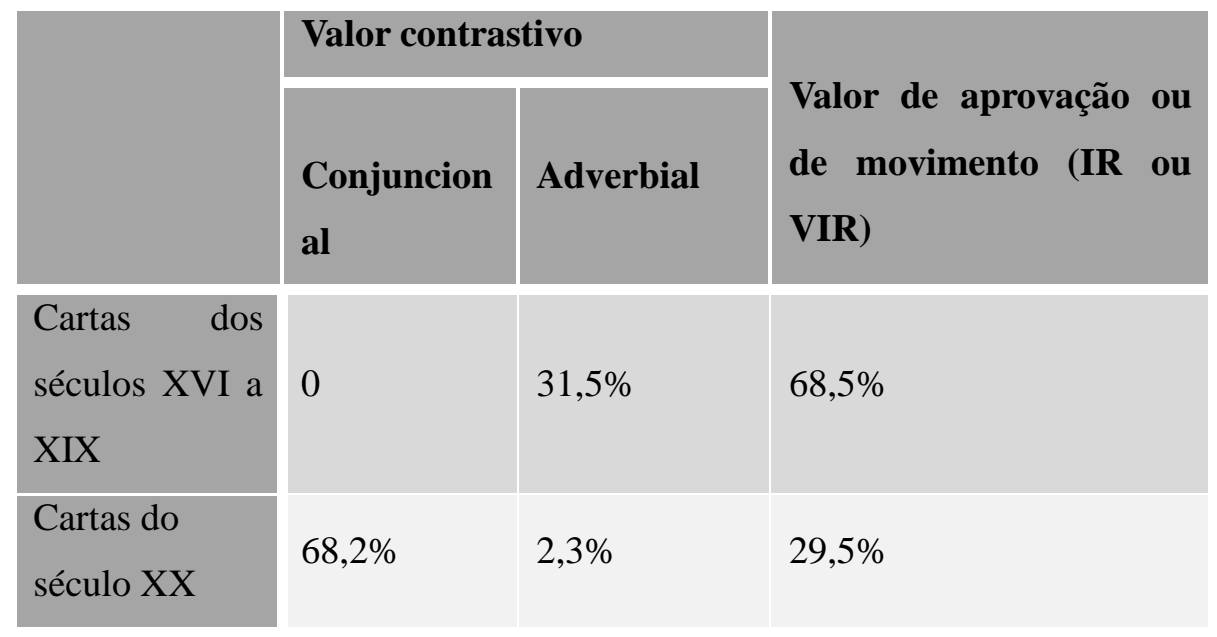

Tabela 2: embora no corpus P.S. e no corpus FLY

Na comparação global das ocorrências de embora nos dois corpora, a média de ocorrências no corpus FLY é de 0,14, ao passo que no corpus P.S. Post Scriptum é de 0,006. Dos 
resultados apresentados na tabela 2, destaca-se, em primeiro lugar, o funcionamento quase exclusivamente conjuncional no século XX, o que confirma a ideia de que esta conjunção é mesmo muito recente. Paralelamente, o uso adverbial deste conector, que sobrevive até ao presente na locução muito embora, é, nestes dados do século passado, bastante residual. Note-se ainda o decréscimo do uso de embora associado a verbos de movimento, sendo particularmente acentuada a diminuição do uso com o verbo vir.

Em síntese, pela análise de cartas do corpus FLY, parece ser necessário esperar pelo século XX para encontrarmos estabilizado o funcionamento conjuncional de embora, ideia que confirma o carácter recente desta conjunção, atualmente uma das mais frequentes no PEC.

\subsection{Algumas hipóteses sobre mesmo que}

A escassez de dados relativos a mesmo que, locução conjuncional típica das condicionaisconcessivas do PEC, é ainda mais acentuada do que a parca frequência de uso de embora. No corpus P.S. Post Scriptum, encontra-se exclusivamente um exemplo de mesmo que, numa carta do século XIX, transcrita no exemplo (16).

(16) Deos permita assim / mesmo que tal assim me não assu/ceda

(CARDS6139, 1825)

A análise contrastiva do conjunto de cartas de Marquesa de Alorna, mais formais e mais argumentativas, confirma a quase inexistência de exemplos, havendo também apenas um caso de uso de mesmo que, o qual se transcreve em (17).

(17) mas também grande fraqueza seria a minha, se não sustentasse, mesmo na sua augusta presença, que o meu coração fiel e puro merece a V. A. R. mesmo que me dê inteira confiança neste ponto

(Marquesa de Alorna, Tycho Brahe) 
Nos dois exemplos, porém, o funcionamento desta locução parece ser já em tudo semelhante ao do português contemporâneo: ocorre em posição pré-verbal, seleciona conjuntivo (em ambos os casos, presente do conjuntivo) e introduz um enunciado condicional com valor hipotético.

Se o facto de serem apenas dois exemplos não permite extrair qualquer conclusão, a consulta do Corpus Lexicográfico do Português permite colocar a hipótese de que se trata de uma locução conjuncional também bastante inovadora, dado que não existe qualquer entrada autónoma para mesmo que como locução conjuncional, ao contrário do que se verifica para embora e para ainda que. Além disso, entre as 62 entradas de mesmo nas obras lexicográficas do CLP, não há qualquer atestação da sua ocorrência como concessivo.

A pesquisa desta locução na escrita de cartas do século XX do FLY não é mais esclarecedora, havendo apenas 4 exemplos de mesmo que, conjunção especializada no valor condicional-concessivo e uma das mais frequentes no PEC.

\subsection{A maturidade de ainda que}

Em contraste com a escassez de dados para embora e com a inexistência de dados para mesmo que, no corpus P.S. Post Scriptum há 114 ocorrências de ainda que. A tabela 3 apresenta a sua distribuição por século.

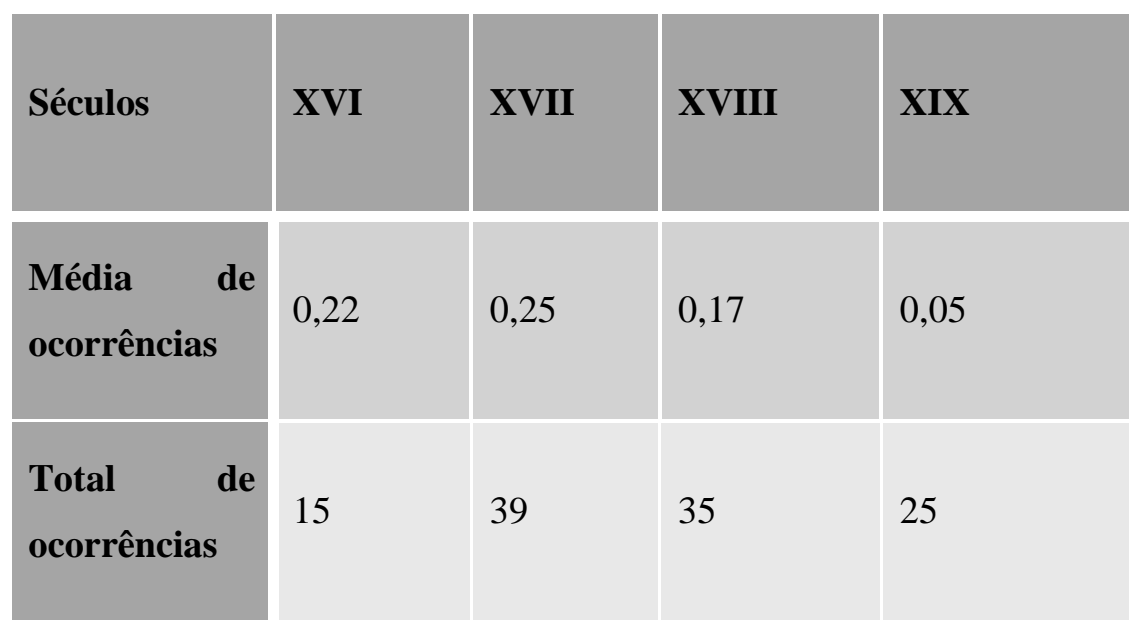

Tabela 3: ocorrências de ainda que / inda que no corpus P.S. 
Comparando as médias nos quatro séculos analisados, verifica-se que o valor médio de frequência de uso se mantém estável até ao século XIX, século em que parece ter havido um declínio na frequência de uso da locução ainda que / inda que.

Quanto aos valores semânticos operados por esta locução ao longo da Idade Moderna, encontram-se entre os dados contextos que atestam a sua plurifuncionalidade semântica, à semelhança do que acontece no PEC. De acordo com a breve descrição apresentada no ponto 4., a locução ainda que pode operar tanto valores de condicionais-concessivas como o valor factual das concessivas canónicas (cf. exemplos 5 a $5^{\prime \prime}$ ). Pelo menos na norma do português contemporâneo, esta locução seleciona sempre um tempo do modo conjuntivo. No exemplo (18), a concessiva de ainda que constrói-se com presente do conjuntivo e, à semelhança do que se descreve para o PEC (Costa, 2008; 2010), é potencialmente ambígua entre o valor factual e o hipotético, podendo interpretar-se que o referente pode vir a dizer que não foi recebido em face da Igreja (valor hipotético) ou que anda mesmo a dizer que não foi recebido em face da Igreja (valor factual).

(18) aimda / q(ue) digua q(ue) não foy recebido em face / de igr(ej)a foy casado cõ toda a / pertencão q(ue) / podia ser porq(ue) o p(adr)e di(og)o mont(eir)o os recebeo (CARDS3127, 1601)

$\mathrm{Na}$ análise deste caso de ambiguidade, salientam-se as vantagens de um corpus como o P.S. Post Scriptum, o qual faz acompanhar a edição do texto, que constitui o corpus linguístico, de informação relativa ao contexto de produção de cada carta. $\mathrm{Na}$ verdade, há informações no processo inquisitorial em que a CARDS3127 está incluída, um processo de culpa de bigamia, que permitem saber que o cunhado do autor, de facto, alegava a nulidade do seu casamento com Inês Rodrigues $^{12}$. Neste caso, na análise linguística, pode classificar-se o exemplo (18) como um caso de concessiva de conjuntivo com valor factual.

$12 \mathrm{O}$ autor desta carta, datada de 1601, é Tomé de Sousa, que escreve à sua irmã, Margarida Dias, de Refoios do Lima, contando-lhe que o cunhado, Francisco Fernandes, se casou pela segunda vez. Margarida Dias denuncia à Inquisição de Lisboa Francisco Fernandes, casado havia 10 
Além desta configuração com conjuntivo, a possibilidade de expressar factualidade com indicativo está bem atestada quer nas produções escritas das cartas, quer em gramáticas até ao século XX. Por exemplo, Epiphânio Silva Dias, na Syntaxe Historica, menciona a possibilidade de o indicativo ser o modo selecionado em concessivas de «caso real», sendo disso exemplo (19) e $(20)$.

(19) sei folgara s(enh)õr de saber de mï novas / amiude aimda q(ue) eu o mesmo dezejo tenho e porem não sei se o cauza de semdo / de meus irmãos se terë pouca vomtade de m' escrever (PSCR0006, 1542)

(20) estamos rezolvidos a annuir aos / rogos de v(ossa) m(er)ce ainda que ha muitas opiniõens que fa/vorecer o Crime he ampiliar a multiplicação do mesmo

(CARDS5041, 1823)

Tanto em (19), um exemplo de uma carta ainda da primeira metade do século XVI, como em (20), exemplo do século XIX, o modo selecionado na concessiva é o indicativo. No primeiro caso, estabelece-se um contraste factual entre, efetivamente, ter vontade de receber novas e poucas notícias receber e, no segundo caso, um contraste entre a decisão de anuir aos rogos do destinatário, apesar de opiniões contrárias a essa decisão.

Nos exemplos (18), (19) e (20), o valor semântico de ainda que é equivalente ao valor de embora. Em (21), ilustra-se uma condicional-concessiva com presente do conjuntivo e com valor hipotético.

(20) ainda que caiam raios / sobre mim nan / me hei de disdizer (CARDS2229, [1654])

anos com sua irmã Inês Rodrigues, da qual teve quatro filhos. Francisco Fernandes tinha mudado de nome para Gaspar Ferreira e tinha casado com outra mulher em Lisboa. O réu morreu de doença nos cárceres em 1608. 
O valor hipotético de (21) pode ser evidenciado por uma paráfrase como (21'), com a comutação do conector por mesmo que.

(21’) Mesmo que caiam raios sobre mim, não me hei de desdizer.

Os exemplos (18) a (21) dão conta da plurifuncionalidade de ainda que ao longo da Idade Moderna. Por outro lado, a comparação da análise das cartas do P.S. Post Scriptum com dados de outros corpora confirma uma elevada frequência de uso de ainda que entre os conectores concessivos deste período.

Em primeiro lugar, verifica-se que ainda que é o conector concessivo mais usado nas cartas de Marquesa de Alorna, com 14 ocorrências num total de 16 conectores concessivos contabilizados, como se observa na tabela 4.

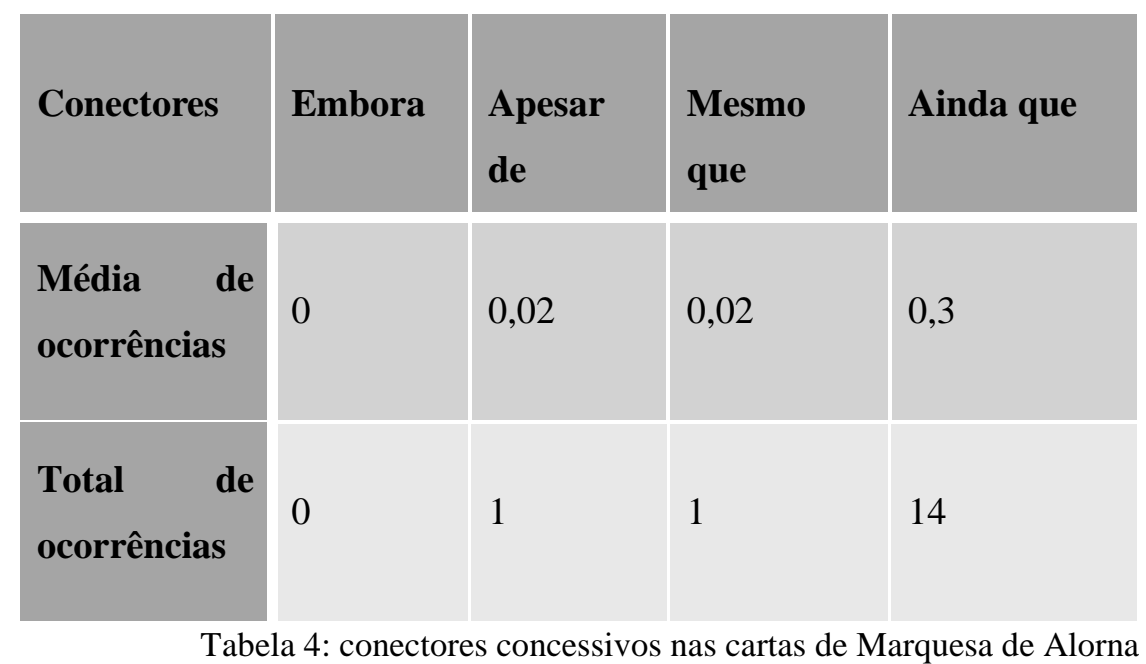

Em segundo lugar, considerando no Corpus Lexicográfico Português exclusivamente as ocorrências em que a grafia deste conector junta as palavras, ainda ou inda e que, atestam-se 95 ocorrências de indaque e 399 ocorrências de aindaque, como a que se exemplifica em (22).

(22) A este nome, aindaque do genero masculino, sempre lhe dá Plinio epitheto 


\section{Rafael Bluteau (1712-28) Vocabulario Portuguez e Latino (CLP)}

Em terceiro lugar, a par da estabilidade atestada em obras lexicográficas, a locução ainda ou inda que aparece descrita em gramáticas do período em estudo já com o uso conjuncional e subordinativo ${ }^{13}$ que lhe conhecemos no português contemporâneo. Disso é exemplo o excerto em (23), da Grammatica Philosophica de Jeronimo Soares Barbosa.

(23) Estas conjuncções mas, porêm suppõem dantes outra proposição, que he a principal; mas não outras conjuncções adversativas, que liguem tambem a principal com a subordinada, quaes não temos. Temos porêm para a principal as formulas Bemque, Postoque, Ainda ou Indaque, e antigamente Enque.

Barbosa, Jeronymo Soares (1880) [1822] Grammatica Philosophica da Lingua Portugueza, p. 355

Finalmente, encontra-se uma descrição do funcionamento de ainda que conforme com os dados dos séculos XVI e XIX e, simultaneamente, com o português contemporâneo na Syntaxe Historica Portuguesa, como se pode verificar na transcrição em (24).

(24) ainda que e (actualmente na conversação familiar e no verso) inda que tem significação geral concessiva e empregam-se tanto quando a or. enuncia um caso supposto, como quando enuncia uma realidade

Augusto Epiphanio da Silva Dias (1918) Syntaxe Historica Portuguesa, p. 292

13 Considera-se que esta descrição atribui a ainda ou inda que um funcionamento conjuncional subordinativo na medida em que se interpreta «principal» como «primeira», ou seja, a oração anteposta. Neste sentido, este excerto ilustra a diferença entre conjunções coordenativas contrastivas (adversativas), como mas, que só podem ocorrer no segundo termo oracional (supõe antes outra proposição), e conjunções subordinativas contrastivas, como ainda que, cuja oração que encabeçam aparece anteposta em relação à frase. 
E, curiosamente, o exemplo que acompanha esta descrição da plurifuncionalidade semântica de ainda que é um exemplo que remonta ao século XVI, dos Diálogos, de Heitor Pinto $^{14}$.

(25) Isto fazë os principes alheos de soberba, ca os inchados della, inda que vejão seus erros, ham-se por abbatidos em os emendar (H.P., I. 203).

(ibidem)

Contudo, mais uma vez, é o olhar pelos dados do início do século XX que permite completar a história do percurso deste conector. Pela análise das cartas do FLY, justamente na altura em que se publica esta obra de Epiphanio Silva Dias, a frequência de uso de ainda que parece estar em declínio. Ao contrário do que se observou para embora, nas cartas produzidas século XX, há apenas uma ocorrência de ainda que, transcrita em (26).

(26) um dia que / modifiques a vida ou seija casares ainda que / muita vontade que se tenha não se consegue

(FLY1371, 1969)

Esta única ocorrência de ainda que no corpus FLY, além de indiciar um uso residual deste conector (em confronto, por exemplo, com embora), surge num enunciado estruturalmente degradado, no qual o autor parece desconhecer a sintaxe própria de ainda que, embora o associe a um valor próximo do contrastivo, eventualmente num configuração paralela à de por muito que, conector pertencente ao mesmo paradigma.

Em suma, os resultados da análise das concessivas usadas nas cartas do FLY indiciam um cruzamento das histórias de embora e de ainda que, testemunhando a tendência de crescimento do primeiro e o decréscimo de uso do segundo.

14 Heitor Pinto (1528?-1584). 


\section{Considerações gerais: algumas pistas para o percurso diacrónico de conectores concessivos}

Apesar da escassez generalizada de dados, algumas ideias podem ser formuladas enquanto considerações gerais, deixando em aberto a necessidade de se alargar a análise às cartas que entretanto estão a ser tratadas e integradas no corpus P.S. Post Scriptum. De qualquer forma, a presente análise de cartas dos séculos XVI a XIX confirma a ideia de que o percurso de embora e de mesmo que até à sua estabilização como conjunções subordinativas é longo e estava ainda a meio caminho no português da Idade Moderna.

A falta de dados para mesmo que impede qualquer tipo de conclusão, observando-se apenas que, nos dados encontrados, este ocorre já com uma distribuição conjuncional, expressando um dos valores de condicionais concessivas, o hipotético.

Quanto a embora, a análise apresentada robustece a hipótese de que, ao longo do período em análise, este conector funcionou predominantemente com distribuição adverbial, estando em curso a sua fixação quer no valor contrastivo, quer no valor de movimento associado a verbos como ir e vir. Tanto quanto os dados considerados permitem concluir, é preciso esperar pelo século XX para se verificar a sua consagração como conjunção concessiva.

Ao contrário, os dados analisados evidenciam ainda que como locução conjuncional plurifuncional nos valores factual e hipotético, com um funcionamento bastante estável, tal como a conhecemos hoje, tanto na sua gramática, como na frequência de uso.

Relativamente a esta conjunção, parece ficar também em aberto a hipótese de que o declínio de frequência de uso, que teve início no século XIX e se acentuou nos dados do século $\mathrm{XX}$, se possa relacionar com a estabilização do uso de embora, que preenche o valor factual, e, eventualmente, com a expansão de mesmo que, que cobrirá os valores condicionais - hipotético e contrafactual - antes predominantemente expressos por ainda que. O percurso cruzado de embora e de ainda que aparece representado em termos de frequências médias de ocorrência na figura 1. 


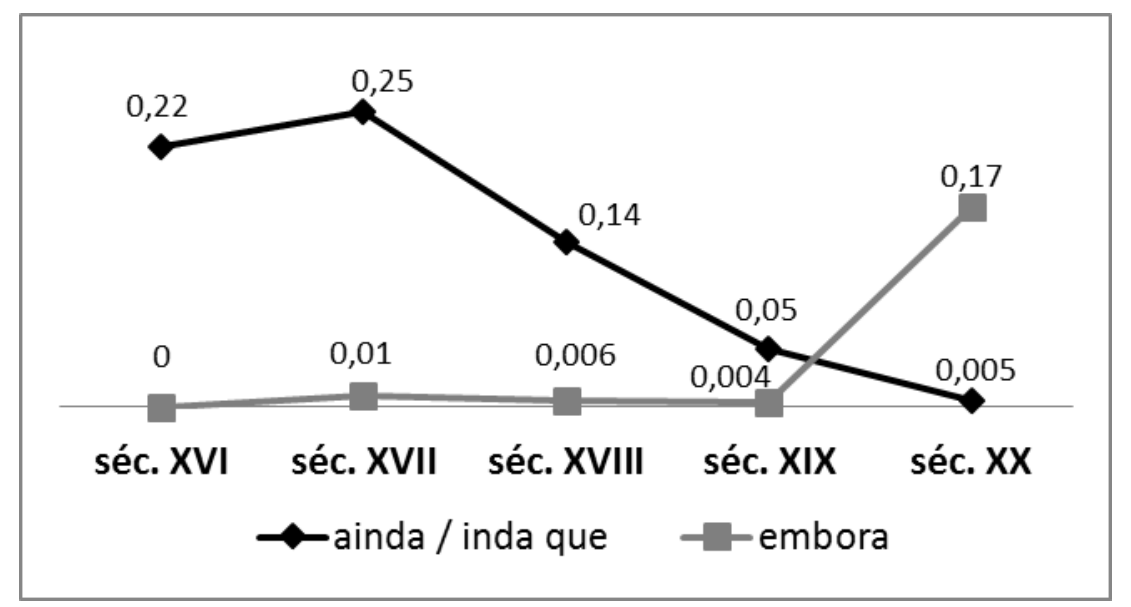

Figura 1: Frequência de uso de embora e ainda que

Esta hipótese sobre frequências de uso conduz a um regresso aos dados de desenvolvimento linguístico e à escala de frequência apresentada em (2), que colocava ainda que entre os conectores menos usados no corpus de aquisição de Costa (2010). Na verdade, neste corpus, a locução ainda que só é usada por adultos, sendo que as crianças usam embora e apesar de para expressar contraste concessivo. A explicação destes resultados, que apontam para uma preferência das crianças pelos conectores que veiculam apenas um dos valores semânticos, residiu principalmente na complexidade semântica de ainda que, rejeitando-se a hipótese de frequência no input. Com os resultados apresentados, parece que a saliência de embora em termos frequência de input será outro aspeto a ter em consideração na explicação da ordem de aquisição dos conectores concessivos, ainda que esta característica do input também possa, ela própria, ser explicada em termos da complexidade estrutural associada a cada conector. 


\section{Referências}

\section{Referências bibliográficas}

Brito, Ana Maria (2003) Subordinação Adverbial. In Mateus et al. Gramática da Língua Portuguesa, pp. 695- 728.

Costa, Ana (2010). Estruturas contrastivas: desenvolvimento do conhecimento explícito e da competência de escrita. Dissertação de doutoramento, Universidade de Lisboa. (2008) Para a Descrição da Plurifuncionalidade de ainda que. In Estudos Linguísticos. Revista do Centro de Linguística da Universidade Nova de Lisboa. Lisboa: Colibri, pp. 161177.

Costa, Ana, García Prieto, Elisa e Pampliega Pedreira, Víctor (2014) Public versus private through letters. Comunicação apresentada no Encontro Reading and writing from below exploring the margins of modernity (Helsínquia, 20 a 22 de agosto).

Elspaß, Stephan (2012) Between linguistic creativity and formulaic restriction. In Dossena, M. \& Camiciotti, G. L. (eds.). Letter Writing in Late Modern Europe. Amsterdam/Philadelphia: John Benjamins, 45-64.

Flamenco García (1999) Las Construcciones Concesivas y Adversativas. In Demonte, Violeta y Bosque, Ignacio (Dir.) Gramática Descriptiva de la Lengua Española - 3 - Entre la Oración y el Discurso. Madrid: Espasa-Calpe, 3805-3878.

Lima, José Pinto de (1997) Caminhos semântico-pragmáticos da gramaticalização: o caso de embora. In Brito et al. (orgs.) O Sentido que a Vida Faz. Estudos para Óscar Lopes. Porto: Campo das Letras, pp. 643-655.

Lobo, Maria (2003) Aspectos da Sintaxe das Orações Subordinadas Adverbiais do Português. Dissertação de Doutoramento, Universidade Nova de Lisboa.

Lopes, Óscar (1989) Construções concessivas. Algumas reflexões formais lógico-pragmáticas. Comunicação

apresentada no XIX Congreso Internacional de Linguística e Filoloxia Românicas (Santiago de Compostela).

agora in Oliveira, F. e Brito, A. M. (coord.) (2005) Entre a Palavra e o Discurso. Estudos de Linguística 
1977-1993. Porto: Campo das Letras, pp. 193-209.

(1983) Sobre as contrastivas em Português. Agora in Oliveira e Brito (coord.) (2005)

Entre a Palavra e o Discurso. Estudos de Linguística 1977-1993. Campo das Letras: Porto, pp. 177-191.

Martins, Ana Maria (2003) Relatório da cadeira de História da Língua Portuguesa. Relatório apresentado a concurso para Professor Auxiliar, Faculdade de Letras da Universidade de Lisboa.

Marquilhas, Rita (2012) A historical digital archive of Portuguese letters. In Dossena, M. \& Camiciotti, G. L. (eds.). Letter Writing in Late Modern Europe. Amsterdam/Philadelphia: John Benjamins, 31-43.

Rudolph, Elisabeth (1996) Contrast: Adversative and Concessive Relations and their Expressions in English, German, Spanish, Portuguese on Sentence and Text Level. Berlim, Nova Iorque: Walter de Gruyter.

Peres, João (1997) Sobre Conexões Proposicionais em Português In Brito et al. (orgs.) O Sentido que a Vida Faz. Estudos para Óscar Lopes. Porto: Campo das Letras, pp. 775-787.

Peres, João et alii (1999) Sobre a forma e o sentido das construções condicionais em português In Isabel Hub Faria (org.) Lindley Cintra. Homenagem ao Homem, ao Mestre e ao Cidadão. Lisboa: Edições Cosmos, pp. 627-653.

Prada, Edite (2000) Produção de Construções Adversativas no Português Europeu. Dissertação de Mestrado Interdisciplinar em Estudos Portugueses, Universidade Aberta.

Varela, Lina (2000) Para uma Semântica das Construções Concessivas e Adversativas do Português. Dissertação de Mestrado em Linguística, Faculdade de Letras da Universidade de Lisboa.

\subsection{Corpora e outras fontes}

Corpus PS-CARDS: http://ps.clul.ul.pt/pt/index.php?action=home

Corpus FLY: http://fly.clul.ul.pt/

Corpus Lexicográfico do Português (DICIweb): http://clp.dlc.ua.pt/Inicio.aspx

Corpus Tycho Brahe: http://www.tycho.iel.unicamp.br/ tycho/corpus 
Alorna, Marquesa de (1941) Inéditos - Cartas e Outros Escritos. (selecção, prefácio e notas do prof. Hernani Cidade). Lisboa: Livraria Sá da Costa.

Barbosa, Agostinho (1611) Dictionarium Lusitanico Latinum. Bracharae: typis \& expensis Fructuosi Laurentij de Basto.

Barbosa, Jeronymo Soares (1880) [1822] Grammatica Philosophica da Lingua Portugueza ou Principios da Grammatica Geral applicados á nossa linguagem. 2. edição. Lisboa: Typographia da Academia Real das Sciencias.

Bluteau, Rafael (1712-1728) Vocabulario Portuguez e Latino, vol. 1-4, Coimbra, Colégio das Artes, 1712-1713; vol. 5-8, Lisboa, Pascoal da Sylva, 1716-1721, Suplemento ao Vocabulario Portuguez e Latino, 2 vol., Lisboa, Joseph Antonio da Sylva, 1727, Patriarcal Officina da Musica, 1728.

Dias, Augusto Epiphanio Silva (1918) Syntaxe Historica Portuguesa. Livraria Clássica Editora. Silva, Antonio de Morais (1789) Diccionario da lingua portugueza composto pelo padre D. Rafael Bluteau, reformado, e accrescentado por Antonio de Moraes Silva natural do Rio de Janeiro, Lisboa: Officina de Simão Thaddeo Ferreira. [BBM(Biblioteca Brasiliana Mindlin] http://www.brasiliana.usp.br/bbd/handle/1918/00299210\#page/3/mode/1up)

Vicente, Gil [1562]. [Copilacam de todalas obras de Gil Vicente, a qual se reparte em cinco liuros. O primeyro he de todas suas cousas de deuaçam. O segundo as comedias. O terceyro as tragicomedias. No quarto as farsas. No quinto as obras meudas]. - [Lixboa] : [em casa de Ioam Aluarez]. BND http://purl.pt/11494 